\title{
Flood occurrence hazard forecasting based on geographical information system
}

\author{
${ }^{1 *}$ K. Solaimani, ${ }^{2}$ H. Mohammadi, ${ }^{3}$ M. Z. Ahmadi and ${ }^{1}$ M. Habibnejad
}

${ }^{1}$ College of Natural Resources, University of Mazandaran, Sari, Iran

${ }^{2}$ Watershed Management Department, College of Natural Resources, University of Mazandaran, Sari, Iran

${ }^{3}$ College of Agriculture, University of Mazandaran, Sari, Iran

Received 6 February 2005;

revised 2 July 2005;

accepted 21 July 2005;

onlined 30 September 2005

\begin{abstract}
The application of Geographical Information system (GIS) in modeling flood and its prediction in catchments offers considerable potential. Several examples illustrate simple GIS techniques to produce flood hazard indices or its zonation using hydrologic-type models. Existing flood models can also be loosely coupled to a GIS, such as the HMS (Hydrological Modeling System) model. Forethermore, models can be fully integrated into a GIS by embedded coupling, such as the SCS (Soil Conservation Service) model. Installation of flood forecasting systems in watersheds with incomplete hydrometric data may reduce the flood-induced damages. In this study Geographical Information system used to up to date the watershed data and estimation of SCS model parameters which is sensible to considered the real time flood forecasting in Kasilian catchment of Mazandaran province. The main aim of this paper is to investigate the possibility of the linkage between GIS with a comprehensive hydrologic model, especially HMS. The use of GIS could produce a suitable agreement between observed results (extracted rainfall and runoff data of 1992, 1995 and 1996 from the related stations) with the calculated results of the hydrological model. The obtained results from rainfall-runoff process simulations of the model in this research showed that submergibility of the main watershed, Kasillian, does not depend on the outlet discharge rate of each one of its watershed independently. But it is related to how those two outlet hydrographs from main river watershed are combined. The model is capable of showing the flood characteristics temporally and spatially in each cross section of the channel network.
\end{abstract}

Key words: Flood, GIS, SCS, HMS, Kasillian Watershed, Iran

*Corresponding Author, E-mail: solaimani2001@yahoo.co.uk

\section{Introduction}

With increase in constructions along rivers and concentration of population around submergible areas, the flood-induced damages are increasing. The complete flood protection with installation of great flood control structures like flood dams are not justified due to its high cost. It is not environmentally, socially and economically an optimum idea either. For this reason, the flood forecasting system can have a considerable role in flood management through logical utilization of weir gates and dam reservoirs. In this direction, different systems have been innovated in different countries of the world (Williams, 1994; Xiaoliu, 2000; Olivera and Maidment, 1998). But the lack of equipment and tools and also high cost of installation are the limiting factors in our country. Recently, the flood return period has decreased in northern Iran, so a suitable method of decreasing the flood-damages is required, by flood forecasting. The study area is an ideal location for this purpose. The overall aim of this study is to find out the efficiency of GIS to create the main inputs to simulate a comprehensive hydrological model. The main requirement of a hydrological model are the description of flow channel characteristics and land surface as input to watershed model. The flood forecasting is in fact the development and perfection of the applied engineering hydrology and its aim is to obtain real time data of rainfall and river flow by short wave, radio and satellite network and using them in rainfallrunoff models to forecast floods in consecutive time and space intervals (Cabal and Erlich, 1992). The quality of flood forecasting systems depends mainly on the quality and the amount of basic collected data about hydrology and the hydrological yield of the corresponding watershed (Ammentorp, et al., 1992). The Kasillian watershed is located from $53^{\circ} 18^{\prime}$ to $52^{\circ} 60^{\prime} 30^{\prime \prime}$ east longitudes and $36^{\circ} 7^{\prime}$ to $35^{\circ} 58^{\prime} 30^{\prime}$ ' north latitude, in northern Iran and north of Alborz Mountain. The basin is limited in north to $1100 \mathrm{~m}$. and $1790 \mathrm{~m}$. Haraz altitudes, in south to $2700 \mathrm{~m}$. and $3349 \mathrm{~m}$. altitudes, in west to $2043 \mathrm{~m}$. altitude 
and in east to $1613 \mathrm{~m}$ altitude. The total area of the Kasillian watershed is $67.8 \mathrm{Km}^{2}$, with mean main channel slope of $13 \%$. This watershed has mountainous regions in the south and forest areas in the north. It has the vegetation kinds of forest, rangelands and agricultural lands. From geological points of view, it belongs to the second, third and fourth era and sediment of the region is from Jurassic, Pelican and quartner era. The mean annual rainfall of the region is $791 \mathrm{~mm}$. by Isohyet method and $816.2 \mathrm{~mm}$. by Theissen method. The precipitation is $55 \%$ rainfall and $45 \%$ snow. The main part of the basin has very humid climate (with Orimlek and Sangedeh stations) and the northern part of the basin with lower elevations has humid climate by De marten method. Based on Emberger method, the middle and northern part has cold humid and southern part of the basin with higher elevations has mountain climates (Mohammadi, 2001). This study which combines GIS with hydrologic model is based on some of the previous research works. Smith (1995) created a hydrological information development system, by using GIS and hydrological watershed parameters such as design storm, soil hydrology, time of concentration, runoff coefficient, etc (Smith, 1995). He used the system for rainfall-runoff model management of north Sulphurs River and confirmed that the accuracy of hydrological models based on data obtained from GIS was very high in flood management and gave accurate results. Olivera and Maidment (1998) used CRWR-PREPRO program (Center for Research in Water Resources a GIS Preprocessor for Lumped Parameter Hydrologic Modeling Programs), obtained primary stages data of GIS including the elevations, separated the reach network and sub-basins, recognized the hydrological elements, created continuity among them and finally input them in the hydrological model (Olivera and Maidment, 1999). The results obtained from using CRWR-PREPRO showed that determination of spatial parameters are easy by hydrological model systems and the results can be extendable. Hellweger and Maidment (1997) combined GIS with hydrological model and through CRWR-PREPRO found the required parameters in the basin model, like the boundary of the basin and channels as ASCII ( American Standard Code for Information Interchange) file from elevation data and put it through a conversion table to hydrological model (Hellweger and Maidment, 1997).

\section{Materials and Methods}

To recognize the Kasillian watershed, the vegetation, geology, soil and other information are prepared in the form of maps. Then through GIS and evaluation of the effect of the application of pre-processor of GIS for hydrological system, the channel vegetation of the basin is created to obtain a regional model of channel and watershed characteristics. Information from early model of elevations is prepared from GIS processor and is transferred into hydrological model. To create a rainfall model in GIS medium, it has been tried to practically evaluate it in the hydrological model. To compare the results of hydrological model with observed flow data for calibration of the model, the evaluation of the correctness of the input to the model and the modeling system have been performed. The curve numbers of the SCS (CN) and water velocity in different reaches of channel network in GIS medium were obtained for three cases of (I, II, and III), runoff production of low and medium and an almost saturated soil. Krepcho (1997) calculated CN through GIS in northwest watersheds of Turkey (Kupch, 1997). The same method was used for Kasillian basin. i.e. the hydrological maps of land use which were prepared before and their accuracy was confirmed by field observations, have been converted to elevation files and were put in the GIS medium and then a new layering was obtained from them. To determine the water velocity in the selected reaches, a cross section was surveyed between the highest and lowest main channels in each hydrological unit. These sections should be regular and constant in shape. After estimation of roughness coefficient by Chow, et al. (1988) method, the water velocity was calculated for the main river and each tributary using Manning equation. The lag time of the sub-basins was calculated from US-SCS formula described by Chow, et al:

$\left.\mathrm{Tc}=\mathrm{L}^{0.8} \mathrm{~W}[(1000 / \mathrm{CN})]-9\right]^{0.7} 31.68 \mathrm{~S}^{0.5}$

Where Tc is the lag time in minutes or the time between the center of effective rainfall to peak time of hydrograph, Lw is the length of the longest channel in sub-basin in $\mathrm{ft}, \mathrm{CN}$ is the average curve number and $\mathrm{S}$ is the slope of the longest channel (\%). Reach parameters like length, routing method, $\mathrm{K}$ and $\mathrm{X}$ of Muskingum in sub-basins and water velocity are given to the model as input.

$\mathrm{K}=\mathrm{L} / \mathrm{V}$

Where $\mathrm{K}$ is storage coefficient, which is part of 
output discharge rate, $\mathrm{L}$ is the length of the reach and $\mathrm{V}$ is the average water velocity. $\mathrm{X}$ is between $0-5$ and is calculated from following equation:

$\mathrm{X}=\mathrm{S}^{1 / 2} \mathrm{NP}^{2 / 3}$

Where $\mathrm{S}$ is the river slope in $\mathrm{m} / \mathrm{m} \mathrm{N}$ is the Manning roughness coefficient and $\mathrm{P}$ is the wetted perimeter. After creation of all information layers in Avcview and Avcinfo, all errors are investigated so that they can be executed in GIS medium. To prepare hydrological model of rainfall, some floods of Valikben station, which had the same-duration and single rainfall have been selected. Hyetographs of daily rainfall of Sagdeh and Valikben stations were fitted statistically and the rainfall-runoff events of the watershed have been chosen. In this research, the calibration of the model was performed automatically. For this purpose, after putting all information into the model, the simulation was started for Kasillian basin, and the results were optimized after comparisons with the observed hydrograph in the outlet. The creditability for $2 / 3$ of the events in each of the antecedent moisture (I, II) was used, so that the model could test for creditability in each antecedent moisture content separately.

\section{Results}

After inputting the data into GIS medium and obtaining the $\mathrm{CN}$ information, water velocity in the reaches, calibration and creditability of the model and the results from simulation of the rainfall-runoff events, the submergibility of the sub-basins were considered. There was one flood event for the medium moisture condition of (II) and 3 flood events in dry condition of (I). The rainfalls and flow rates used in simulation of flood discharge in Kasillian watershed are shown in Tables 1 and 2. Fig. 1 shows the hydrological elements after execution of GIS model in Kasillian watershed.

This model was inputted in hydrological model as a watershed model with ASCII format. The results of creditability tests of the model in dry (I) and medium moisture (II) conditions:
The amounts obtained in (I) condition for events 2, 3 and 4 are shown in Figs. 2 and 3 as simulated and observed hydrographs in Valikben hydrometry station.

\section{CN values in sub-basins}

After calibration of model for moisture conditions (I) and (II) and testing their creditability, the CN and primary retention (Ia) are summarized in Tables 3 and 4. In Fig. 4 the forecasted amounts of flood in different times are shown. The upper part is for upstream hydrograph of watershed and the lower part is related to Valikben hydrometry station. To determine the flood water stage, the discharge rating equation of Valikben hydrometry station was used:

$\mathrm{Y}=10.929 \mathrm{X}+12.178$

$\mathrm{R}^{2}=0.9481$

\section{Discussion and Conclusion}

As most Iranian watersheds are submergible and the water resources plans are in progress, use of flood forecasting models and techniques like GIS became more important than before. That is because the method is a combination of management and structures issues which makes the system more efficient and decreases the flood -induced damages. This research which is to investigate the efficiency of using GIS as a preprocessor for a comprehensive hydrological model and to improve the flood forecasting systems in Kasillian watershed is a new gate in comparison to other research works on this subject and in Iran and other neighboring countries. The results of this research can be summarized as follows:

- HECPRERO is an effective tool for simulation and creation of a geographical information bank from watershed levels and transferring it into an acceptable format by hydrological model system.

- At present time there are methods for determination of CN of SCS in GIS and ways to evaluate Muskingum coefficients. These parameters are the main parameters used in this research and it

Table 1: The rainfall data used for simulation of flooddischarge in Kasillian watershed

\begin{tabular}{|cccccc|}
\hline $\begin{array}{c}\text { Rainfall } \\
\text { days before/mm }\end{array}$ & $\begin{array}{c}\text { Recorded } \\
\text { Rainfall/mm }\end{array}$ & Starting time/hr & Ending time/hr & Starting date & Ending date \\
10 & 18 & 13 & 19.30 & 7.10 .92 & 7.10 .92 \\
39.5 & 20.75 & 14 & 16.15 & 16.6 .95 & 16.6 .95 \\
19 & 28.91 & 14.45 & 15.45 & 13.10 .95 & 13.10 .95 \\
26 & 17.99 & 10 & 23 & 7.10 .96 & 7.10 .96 \\
\hline
\end{tabular}




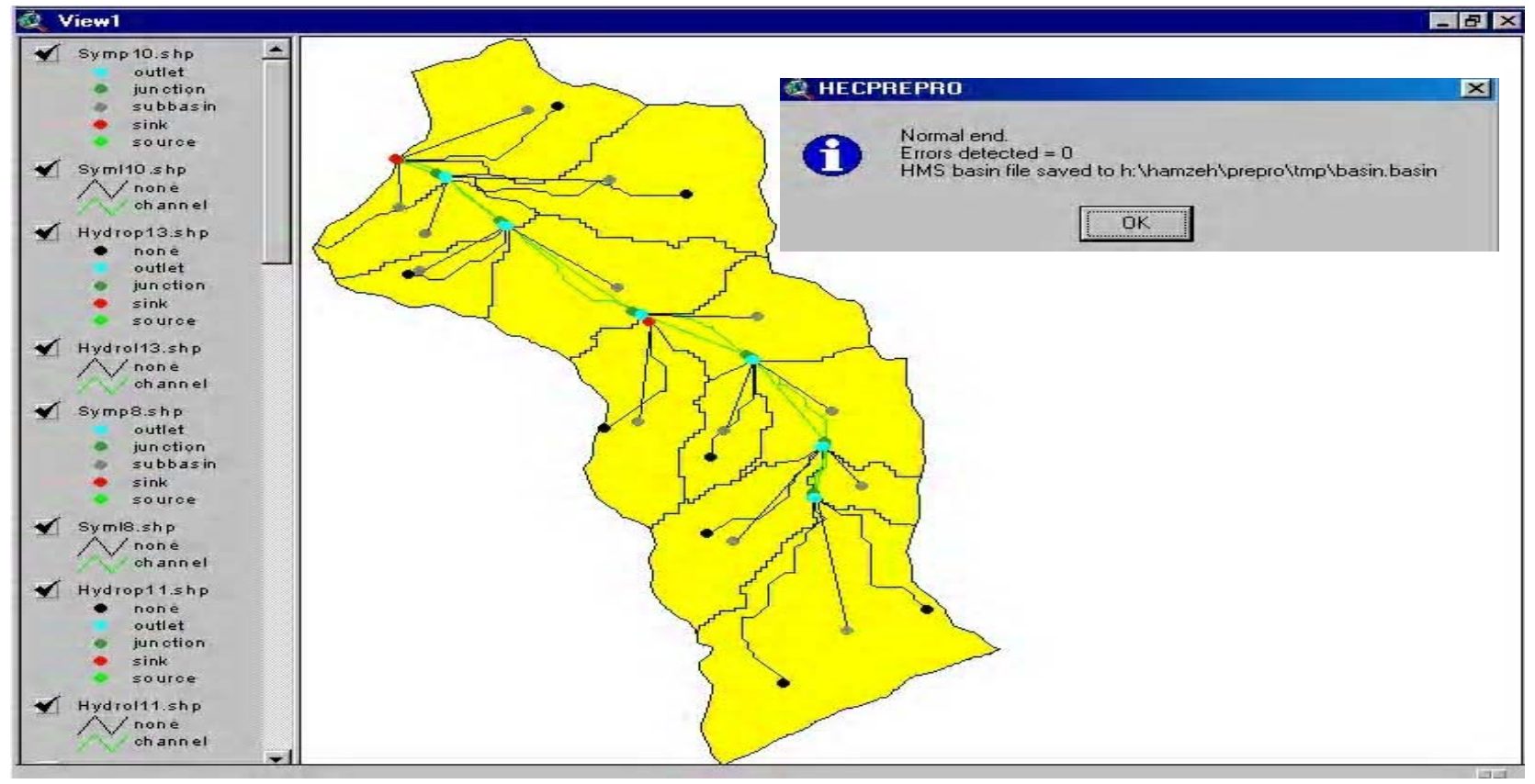

Fig. 1: End of GIS model execution and formation of hydrological model system files

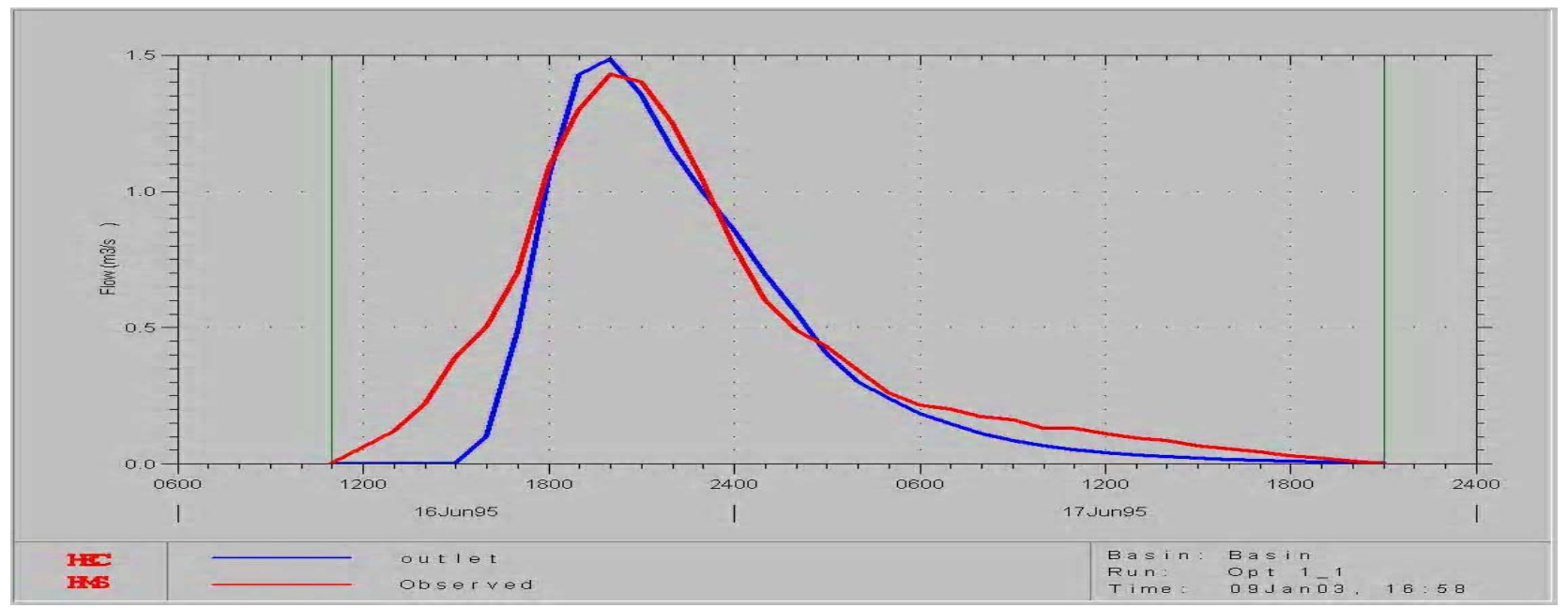

Fig. 2: The simulated and observed hydrographs in Valikben hydrometry station for the event 2 in (II) condition (after optimization)

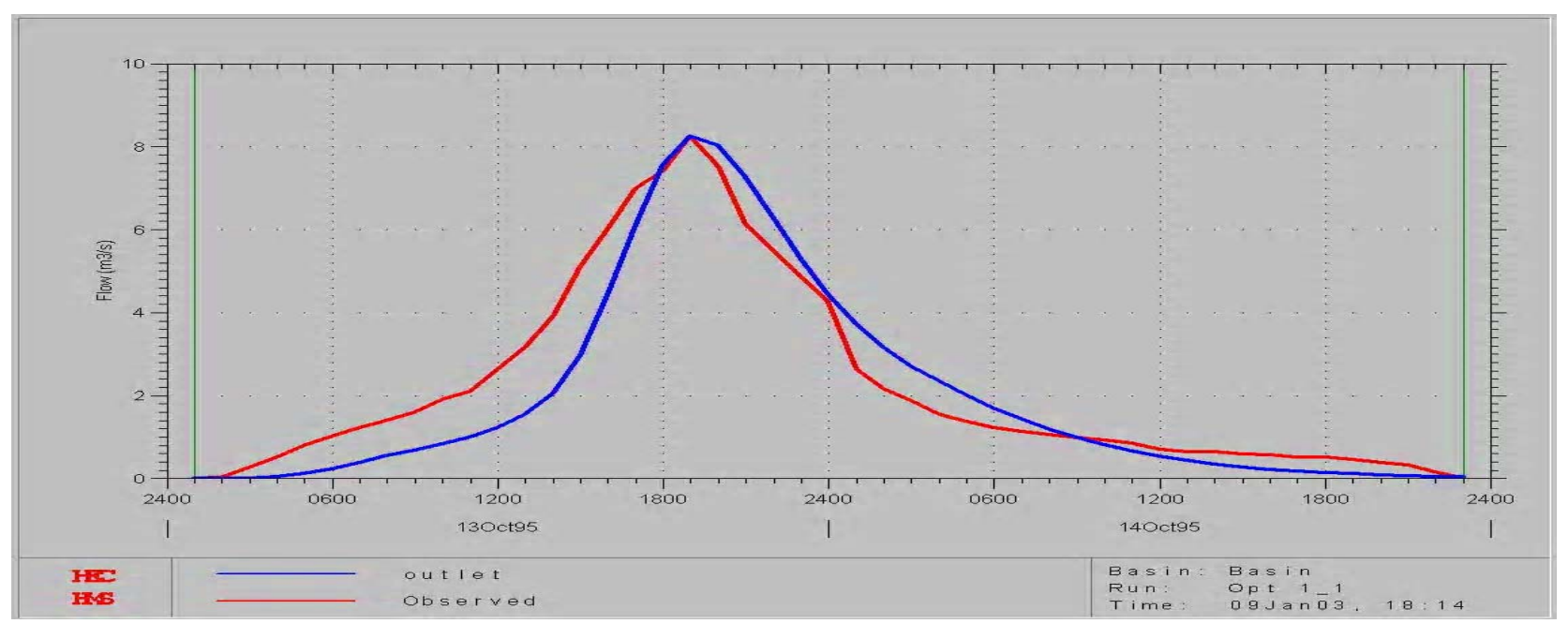

Fig. 3: The simulated and observed hydrographs in Valikben hydrometry station for the event 3 in (I) condition (after optimization) 
Flood occurrence hazard...

Table 2: The flow rates used for simulation of flood discharge in Kasillian watershed

\begin{tabular}{|cccccc|}
\hline $\begin{array}{c}\text { Volume of } \\
\text { water recorded } \\
\text { in Valikben } / \mathrm{m}^{3}\end{array}$ & $\begin{array}{c}\text { Volume of } \\
\text { flood recorded } \\
\text { in Valikben/ } \mathrm{m}^{3}\end{array}$ & Starting time/hr & Ending time/hr & Starting date & Ending date \\
34.02 & 67.8 & 17 & 24 & 7.10 .92 & 9.10 .92 \\
26.93 & 51.8 & 11 & 21 & 16.6 .95 & 17.6 .95 \\
70.22 & 390.71 & 1 & 23 & 13.10 .95 & 14.10 .95 \\
31.27 & 103.34 & 15 & 23 & 7.10 .96 & 9.10 .96 \\
\hline
\end{tabular}

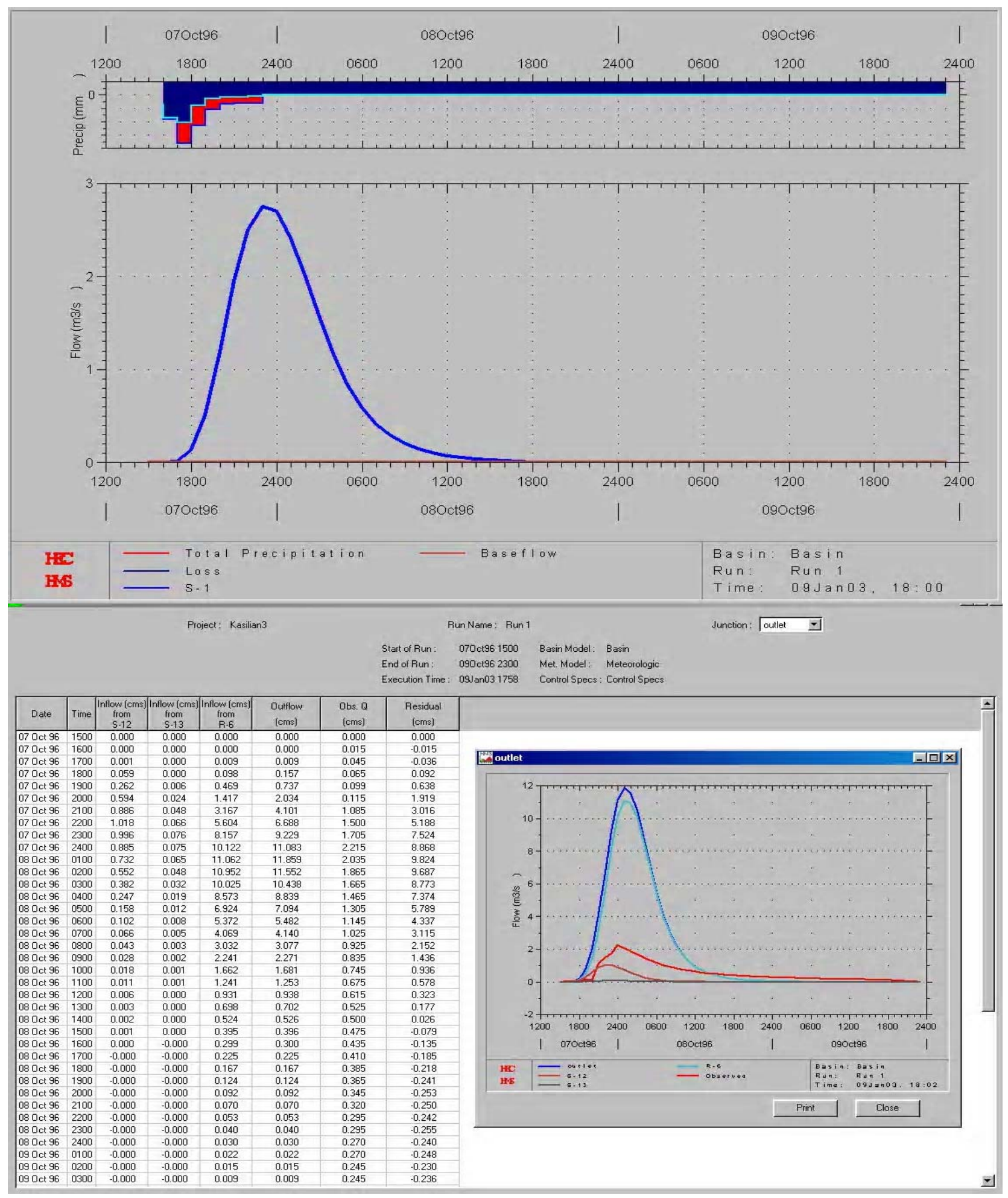

Fig. 4: Simulated flood hydrograph of 7.10.96 event in upper and lower (Valikben) stations 
Table 3: Values of CN and Ia after calibration in condition (I)

\begin{tabular}{|ccccccccccc|}
\hline S1 & S3 & S4 & S7 & S8 & S10 & S11 & S12 & S13 & $\begin{array}{c}\text { Hydrological } \\
\text { Characteristics }\end{array}$ & AMC \\
2.75 & 75 & 74 & 74 & 80.4 & 77.8 & 74 & 77.3 & 80 & CN & \\
76.16 & 16.61 & 17.8 & 17.8 & 12.3 & 14.5 & 17.8 & 14.9 & 12.7 & $0.2 S$ & I \\
\hline
\end{tabular}

Table 4: Values of CN and Ia after calibration in condition (II)

\begin{tabular}{|lcccc|}
\hline S8 & S12 & S13 & $\begin{array}{c}\text { Hydrological } \\
\text { Characteristics }\end{array}$ & AMC \\
87 & 90.2 & 86 & CN & \\
7.59 & 5.519 & 8.27 & $0.2 S$ & II \\
\hline
\end{tabular}

has been recognized that use of GIS determines them accurately. This accuracy makes the calibration methods faster.

In this study evaluation of the efficiency and use of GIS in hydrological model system was successful. GIS as a suitable technique prepares the great and accurate files of the watershed and is favorable for locations with ground data available. For example, the rainfall distribution and conversion to readable format by hydrological model system which combines these components in an applied hydrological models.

The results of simulation of rainfall-runoff process in this investigation showed that the submergibility of the main watershed does not depend to flow rate of each of its watershed independently, but it is related to combination of the outlet hydrographs from the main river basin. The model can determine flood characteristics spatially and temporally in each point of the channel network.

Use of hydrological model system based on GIS is suitable for simulation of the watershed and conversion of rainfall to runoff and prediction of peak flow and flood volume. The obtained graphs and data are dependable and the model can be used for dam management if necessary.

The results showed that $\mathrm{CN}$ is more effective than any other factors in submergibility determination and is affected by soil and vegetation. So, improvement of vegetation and soil physical conditions is to be considered in watershed management. Besides, change in $\mathrm{CN}$ is easier than changes in other factors.

\section{References}

Ammentorp H.C., Havno K. and Refsgaard J.C., (1992). Real time flood forecasting. Int. Symp. On Dams and extreme floods, Granada, Spain, 103-111.

Cabal A. and Erlich M., (1992). Design development and implementation of hydrological data base management system for the purpose of real-time flood forecasting. $4^{\text {th. }}$ Int. Conf. on Hydraulic Eng. Software Hydrosoft/92. Billerica, USA, 395-406.

Chow V. T., Maidment D. R. and Mays L. W., (1988). Applied Hydrology. Mc.Graw-Hill Education, New York, 572.

Hellweger F. and Maidment D. R., (1999). Definition and Connection of Hydrologic Elements Using Geographic Data, Journal of Hydrologic Engineering. 4, 10-18.

Kupcho K., (1997). Obtaining SCS Synthetic Unit Hydrograph By GIS Techniques, 12 http://gis.esri.com.

Mohammadi H., (2001). Hydrological analysis of flood forecastin: Kasilaian watershed. MSc thesis, University of Mazandaran, 152.

Olivera F. and Maidment D., (1999) Developing a Hydrologic Model of the Guadalupe Basin / Center for Research in Water Resources, Austin, Texas.

Olivera F. S. and Maidment D., (1998) HEC-Prepro v.2: An Arcview pre-processo for Hec,s Hydrological Modeling System. Centre for research in water resources Austin, Texas.

Smith P., (1995). Hydrologic Data Development System, Master Thesis, Department of Civil Engineering, University of Texas at Austin, 60.

Williams P. B., (1994). Flood control Vs. flood management. Civil Eng., 51-54.

Xiaoliu Y. and Michel C., (2000). Flood forecasting with a watershed model: a new model of paprametre updating. Hydrological Sciences Journal, 4, 537-546. 